\title{
Enterprise Risk Management (ERM) Practices to Achieve Long Term and Sustainable Organization's Goals: Case of Institut Teknologi Bandung (ITB)
}

\author{
Johan Candra \\ Research Scholar, School of Business and Management, ITB, Jakarta
}

\begin{abstract}
Every choice made in the pursuit of objectives has its risks. From day-to-day operational decisions to the fundamental trade-offs in the boardroom, dealing with uncertainty in these choices is a part of the organizational lives. A strategy is nothing more than a commitment to a set of coherent, mutually reinforcing policies or behaviours aimed at achieving a specific competitive goal. In order to ensure the implementation of efforts and the allocation of resources to achieve strategic goals, top management should conduct integrated risk management practices to all activities/initiatives of the organization's management, both individually and collectively. Risk management is an intrinsic part of business planning and decision making. No direction is taken without looking at the potential risks and comparing them against the organization's risk appetite.

This paper aims to research in general the practice of enterprise risk management within Institut Teknologi Bandung (ITB) as a well-known and public-state-owned university in Indonesia. This research concludes that the enterprise risk management implementation is not fully implemented yet within ITB as an enterprise. Almost all respondents agree that the implementation of enterprise risk management has a positive and significant influence on the organization's objectives achievement. Improving university performance overall will require an effective enterprise risk management practice. Author highly recommends ITB to adopt risk management practice based on ISO-31000 standard, and it can be combined with other risk management standards available nowadays if necessary. ITB needs to start the implementation at the soonest as possible, in order to maintain its strategic position as a top university in Indonesia, increase its competitive advantages to compete in the global scale, and at the same time achieving its vision and mission in a long-term and sustainable manner.
\end{abstract}

KEYWORDS: Enterprise Risk Management, Good Corporate Governance, Long-term and Sustainable Goals, Strategy Management, University, Vision and Mission.

\section{INTRODUCTION}

Institut Teknologi Bandung (ITB) is a united collective form of all intellectuals, who have high dedication in advancing science, technology, art, as well as social and humanities, through the Three Pillars of Higher Education. In its journey, ITB has contributed to the birth of many crucial roles in Indonesia. As a university, ITB is a comfortable and steady place for distinct intellectual and cultural activities. ITB provides an academic atmosphere that is open to ideas and experiences, critical and visionary thoughts, accompanied by attitudes that uphold academic freedom in scientific and cultural diversity. In order with the Indonesian community's hopes as well as all ITB people, ITB Academic Senate has assembled the ITB Development Master Plan 2020-2025, which provides the directions for development to make the campus as "a Globally Respected and Locally Relevant". Until today, there are a lot of achievements that have been achieved. Rapid changes that happen nowadays, both national and global scale, must be continuously anticipated and responded critically, creatively, innovatively, with integrity and sovereignty. As an organization, ITB must always be an adaptive learning organization to achieve long-term and sustainable goals.

After decades of brilliant contribution, now is the time for ITB to start over again, strengthening itself to be adaptive for the challenges, and designing transformation strategy for the next hundred years. The steps taken for the transformation of ITB 2025, has main characteristics as follows:

$\checkmark$ Three Pillars of Higher Education activities which facilitate all components of ITB academic community to provide the best performance;

$\checkmark$ Institution that has a national reputation, provide solutions to the nation's problems, and can always keep and enhance the nation's dignity; 


\section{International Journal of Current Science Research and Review}

ISSN: 2581-8341

Volume 04 Issue 12 December 2021

DOI: 10.47191/ijesrr/V4-i12-16, Impact Factor: 5.825

IJCSRR@ 2021

WwW.ijesrr.org

$\checkmark$ Institution with respected academic reputations and equivalents with international partners;

$\checkmark$ ITB graduates that have international quality, with nationalist character, love their motherland, play critical roles at their work activities, have an initiative and innovative attitude, have a pioneering attitude, collaborative, and have integrity;

$\checkmark$ Sustainability of ITB's leadership regeneration that is always capable of transformative in every condition. In principle, the strategy of "Pencapaian Wujud ITB 2025" includes five steps:

1. Restructuring the organization. It will make ITB be able to move agile, adaptive, and efficient. Also, manage the potential human resources as human capital to encourage the achievement of the best achievements; and maximize the utilization of Management Information Systems following best practices to support organizational functions and human performance.

2. Enhancing the revenue through creative and innovative ways, with an emphasis on various activities that are relevant to the transformation implementation.

3. Adopting the Education 4.0 paradigm. The critical factors of Education 4.0 are connectivity in learning, educational experience expansion to a borderless state, accompanied by strengthening students' abilities in critical thinking, complexity or non-linear thinking, interdisciplinary thinking, independent learning, and collective learning.

4. Strengthening overall system and innovation ecosystem with a proven scientific and cultural foundation. Based on this fact, the formulation of a leading research agenda needs to be sharpened with a cross or transdisciplinary approach in order to able to respond to national interests and the dynamics of global science.

5. Change management. The participation of all elements of ITB is very vital in the transformation of ITB. Enthusiasm and commitment are the main things. Visions, goals, and objectives of transformation achievement need to be informed to all lecturers and staff. Communication needs to be continuously maintained and developed.

In fact, the risk management is very rarely implemented in the public sectors or government agencies in Indonesia, despite the fact that in 2008 the government stipulated that government agencies conduct risk assessment as part of internal control system. ITB, as a state-owned university, obtain a lot of pressure from stakeholders to manage risk to achieve better performance. An enterprise risk management program supports better decisions at the top management levels. Risk management does not focus only on eliminating or reducing risk, but on finding a proper balance between risk taking and risk mitigation.

Based on Government Regulation of the Republic of Indonesia No.65/2013 regarding the Statute of ITB, it is required for ITB to implement the risk management across the organization. In fact, there is no formal risk management practice and function yet for many years, since the ITB Statute was enacted in 2013. ITB is struggling in implementing enterprise risk management (ERM) and identifying how, and at what level, to integrate it into its organization.

ITB as a top university in Indonesia with a global ranking at $313^{\text {th }}$ (based on the QS World University Ranking 2021), should implement risk management with other existing management system to achieve its strategic goals to make the campus as "a Globally Respected and Locally Relevant". Top management should conduct enterprises risk management practices to all activities/initiatives of the organization's management, both individually and collectively.

This research is conducted to determine the current condition (As-Is analysis) and best practices in the field of risk management, with below objectives:

1. Determine the existence of risk management concept within organization;

2. Determine the existence of risk management practices to create and protect organization's values, and increase competitiveness advantage;

3. Determine the expectation of risk management model to be implemented within organization in the future; 4 . Benchmark the implementation of risk management from other top university in the world; 5. Recommend an enterprise risk management model that suitable with the organization.

By fully implementing the enterprise risk management consistently together with other management system, author believes and expects ITB can sustain its top position in Indonesia, and improve its global ranking from time to time.

\section{REVIEW OF LITERATURE}

Author uses the Standard ISO-31000 as the major reference of the enterprise risk management implementation that can be applied in any organizations [23]. ISO (the International Organization for Standardization) is a worldwide federation of national standards bodies. ISO-31000:2018 is for use by people who create and protect value in organizations by managing risks, making decisions, 


\section{International Journal of Current Science Research and Review}

ISSN: 2581-8341

Volume 04 Issue 12 December 2021

DOI: 10.47191/ijcsrr/V4-i12-16, Impact Factor: 5.825

IJCSRR@ 2021

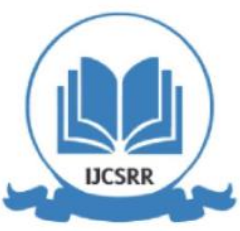

www.ijjesrr.org

setting and achieving objectives and improving performance. Organizations of all types and sizes face external and internal factors and influences that make it uncertain whether they will achieve their objectives. Managing risk is iterative and assists organizations in setting strategy, achieving objectives and making informed decisions. Managing risk is part of governance and leadership, and is fundamental to how the organization is managed at all levels. It contributes to the improvement of management systems. Managing risk is part of all activities associated with an organization and includes interaction with stakeholders. Managing risk considers the external and internal context of the organization, including human behaviour and cultural factors. Managing risk is based on the principles, framework and process, as illustrated in Figure 1 below. These components might already exist in full or in part within the organization, however, they might need to be adapted or improved so that managing risk is efficient, effective and consistent.

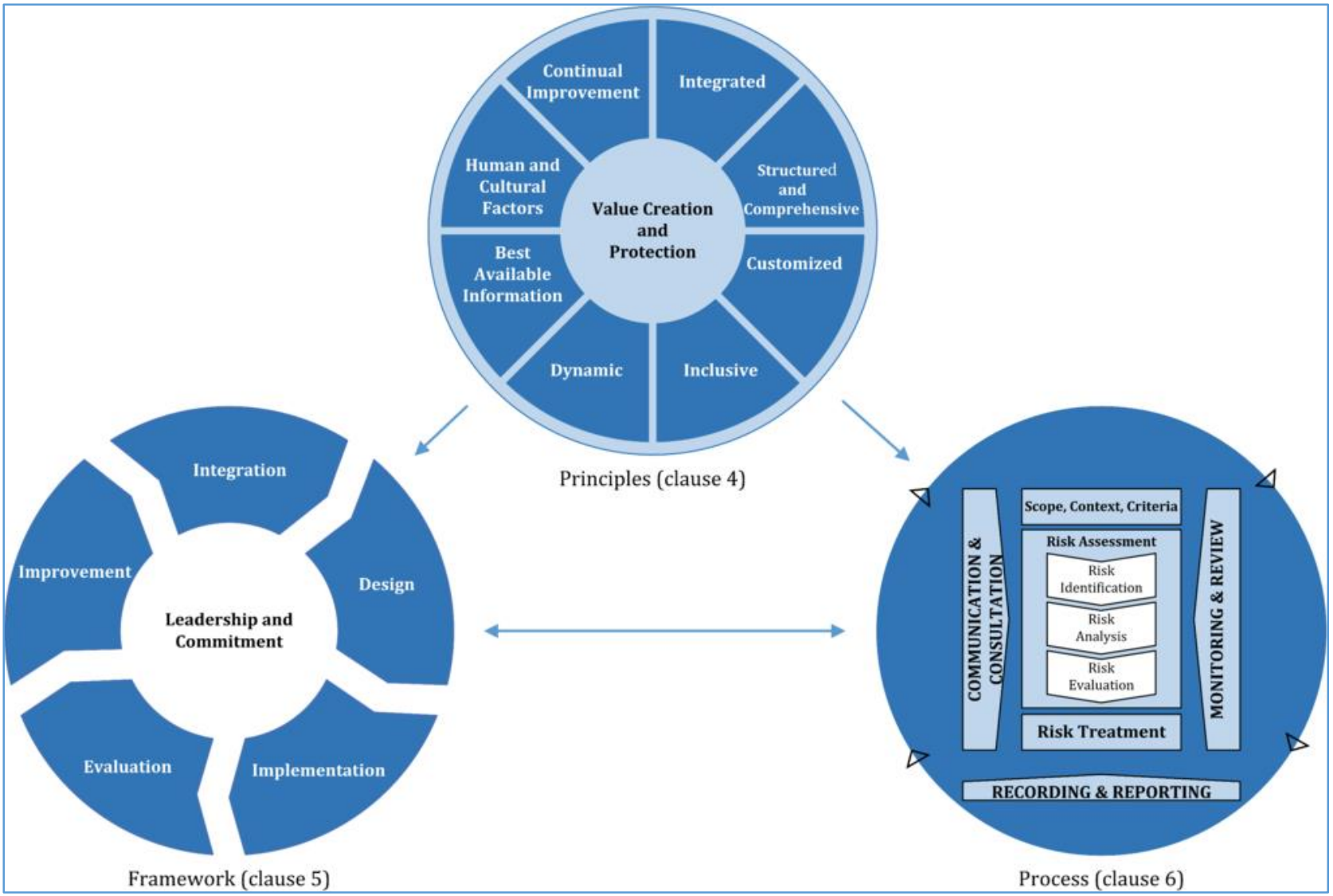

Figure 1. Principles, framework, and process of risk management (ISO-31000:2018)

The purpose of risk management is the creation and protection of value. It improves performance, encourages innovation and supports the achievement of objectives. The principles outlined in Figure 1 provide guidance on the characteristics of effective and efficient risk management, communicating its value and explaining its intention and purpose. The principles are the foundation for managing risk and should be considered when establishing the organization's risk management framework and processes. These principles should enable an organization to manage the effects of uncertainty on its objectives.

The purpose of the risk management framework is to assist the organization in integrating risk management into significant activities and functions. The effectiveness of risk management will depend on its integration into the governance of the organization, including decision-making. This requires support from stakeholders, particularly top management. Framework development encompasses integrating, designing, implementing, evaluating and improving risk management across the organization. The organization should evaluate its existing risk management practices and processes, evaluate any gaps and address those gaps within the framework. The components of the framework and the way in which they work together should be customized to the needs of the organization. 


\section{International Journal of Current Science Research and Review}

ISSN: 2581-8341

Volume 04 Issue 12 December 2021

DOI: 10.47191/ijesrr/V4-i12-16, Impact Factor: 5.825

IJCSRR@ 2021

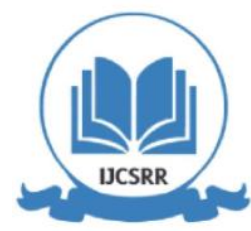

Www.ijcsrr.org

The risk management process involves the systematic application of policies, procedures and practices to the activities of communicating and consulting, establishing the context and assessing, treating, monitoring, reviewing, recording and reporting risk. The risk management process should be an integral part of management and decision-making and integrated into the structure, operations and processes of the organization. It can be applied at strategic, operational, programme or project levels. There can be many applications of the risk management process within an organization, customized to achieve objectives and to suit the external and internal context in which they are applied. The dynamic and variable nature of human behaviour and culture should be considered throughout the risk management process. Although the risk management process is often presented as sequential, in practice it is iterative.

\section{METHODOLOGY}

Author used both primary and secondary data to determine the current condition (As-Is analysis) and best practices in the field of risk management. As-is analysis is being done by using questionnaire and interviews, meanwhile the best practices is being performed by interviewing the subject matter experts and referring to ISO-31000 - RM, COSO - ERM, text book, and benchmarking to other top universities in Indonesia and Singapore. Based on the as-is analysis and best practices, author constructs the gap analysis in order to see how far ITB deviates from the best practices. Author then making conclusion and recommendations for the ITB to be implemented in the near future.

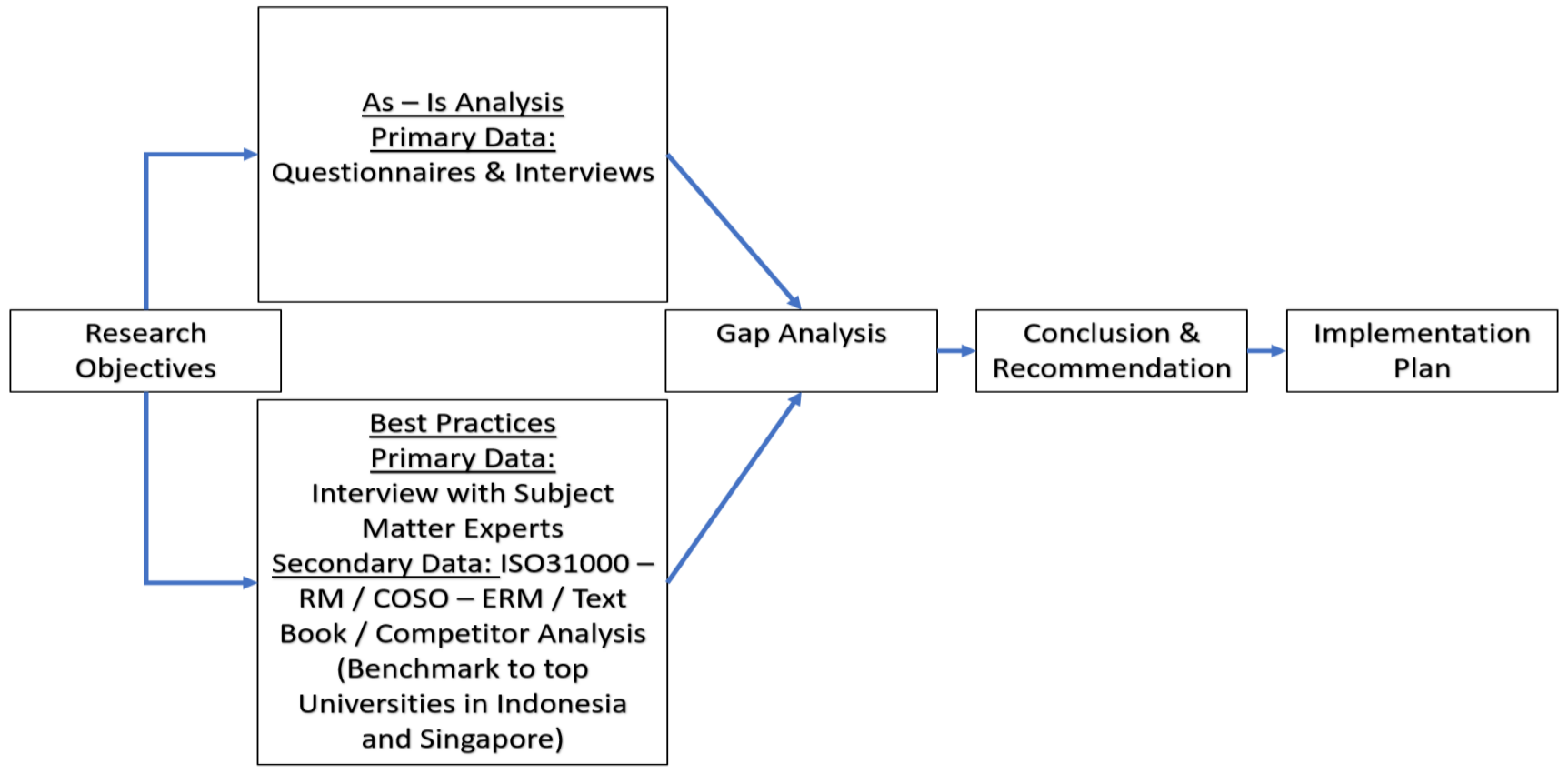

Figure 2. Conceptual framework to be used in this research

For the primary data, Author conducts structured interview to targeted 6 subject matter experts (SMEs) in order to collect information regarding to the challenges, strategy and solution to mitigate those challenges, and the best practices to start implementing the risk management at public sector. Author also conducts structured interview to academic staff of ITB that prefer to be interviewed rather than fill questionnaire questions. In total, 20 academic staff have been interviewed. There are 12 questions to be asked, and the questions are the same with the survey questionnaire. On top of the questionnaire questions, author also add some interview questions, in order to understand more the current as-is situation and what are their expectations regarding the risk management practices. Author has sent the questionnaire to more than a hundred ITB academic staff with various background, where 38 academic staff have participated (20 with interviews and 18 with questionnaires), and 4 staff have declined. There are 12 research questions to be addressed with several options of answer. In addition to the primary data, author also referring to ISO31000 - RM, COSO - ERM, other text books, and benchmarking to other top Universities in Indonesia and Singapore. 


\section{International Journal of Current Science Research and Review}

ISSN: 2581-8341

Volume 04 Issue 12 December 2021

DOI: 10.47191/ijcsrr/V4-i12-16, Impact Factor: 5.825

\section{RESULT AND DISCUSSION}

Below are the key insights taken from the 6 SMEs regarding to challenges, strategies and solution to mitigate those challenges, and the best way to start implementing the risk management in public sector:

1. The inertia condition will create a significant challenge when applying the risk management, due to high resistance within the public organization in accepting the risk management implementation. High inertia in the organization structure, with high complexity to embed risk management function within the organization. The university is in comfort zone that will make the organization in inertia position. This will cause the organization tend to resist any changes, and doesn't want to take necessary risks. The strategy to resolve this situation is start to decrease the level of comfort zone, by decreasing the internal-driven factors, and increasing the external-driven factors. Dare to overhaul the organization structure as a whole, by encouraging the younger generation to take part and become decision maker within the organization.

2. People with high context culture, where the academic staff do not dare to innovate and perform differently. The university tends to follow the trend, rather to become the trend setter. The strategy to resolve this situation is get rid of the attributebased KPIs. The university needs to include the KPIs that give real contribution to the society, for example: KPI based on the number of research papers, and the research results need to be recognized by several institutions.

3. Academic arrogance, where most of the time, the top management in the university are coming from academic staff with the highest academic title (doctorate degree), without considering the essential of the position itself. As a top management, the person must have a high management ability to manage the strategy and risk, and heavy experience in leading people, not only heavy in delivering academic things. This situation will create a significant challenge in regards to risk management implementation that needs high commitment and leadership from the top level to apply another skill of management. The academic staff should have enough professional working experiences, and increase the ability in digital literation.

4. Integrity and competency issues. Many public sector organizations are working ineffectively, which is due considerably to weak standards of governance, integrity, and competency, that result in widespread corruption and low performance.

5. Weak tone from the top regarding to risk management implementation. Most of the time, there is unclear message and commitment from the top management in order to fully implemented the risk management across the organization. Low leadership and commitment towards risk management implementation. This situation can be mitigated by reinforcing the risk leadership and commitment, in a form of risk management charter. In this case, the top management needs to spread the responsibilities to all academic staff within organization.

6. The bureaucracy issue has to be resolved to expedite the service to communities in proper manner. Lack of legal fundamental related to risk management implementation in public sector at national-wide level. In addition, there are coherence problems between one regulation with another. From strategy point of view, the people who dealing with the strategy, investment, and research, are seldom equipped with the norms and regulation, including the risk management practice, and the application of appropriate technology.

The strategy to resolve this situation:

- The central government needs to set up the legal fundamental and determine the risk management model that will be used by public sector at national wide. Along with technology advancement, the public sector will be pushed to implement the risk management within the organization.

- From the external point of view, the Ministry of Education, Culture, Research, and Technology - Higher Education (Kemendikbudrisktek - Dikti) needs to enforce the implementation of risk management within the university by issuing related regulations. The risk management implementation is based on regulatory driven.

- From the internal point of view, the top management needs to realize the benefits and the importance of the risk management practice. The socialization and communication of risk management should be done in organizational wide. The university needs to appoint the figures/experts with strong risk leadership and commitment, as agent of change within the organization. The top management has to ensure the sufficiency of the capability and capacity of the professional staff, along with the budget for the continuous improvement in risk management implementation within the organization.

7. There are still few people within the university who are aware of risk management implementation. Even though the risk management thinking has been applied in daily basis individually, but it is quite new thing for the academic staff in regards of enterprise risk management. Not many academic staff know how to implement the risk management within the 


\section{International Journal of Current Science Research and Review}

ISSN: 2581-8341

Volume 04 Issue 12 December 2021

DOI: 10.47191/ijesrr/V4-i12-16, Impact Factor: 5.825

organization. The strategy to resolve this situation is to implement the risk management in a small scale (pilot project) to demonstrate the positive results of the implementation for the organization. Enhance the knowledge and skill of academic staff, by providing training and certification in risk management. Start from the human resource development. The first target of human resource development was to develop awareness among members of top management leaders on the importance of risk management. Performing the soft approach to build the risk culture within organization. It could be in a form of risk management socialization, training, certification, focus group discussion, etc.

8. There is limited or even no budget for the risk management implementation within the organization. From aspect of funding independence, the university is still unclear on how to seek the funds and spending it to finance publications, papers, and research. The government subsidy is only about $30 \%$ from total budget at university level, and this is only enough to finance research of approximately 4 months ahead. The lack of funds then must be sought from outside. Funding independence will be needed to create business continuity in the future. Rector is responsible to seeking the funds, and therefore the top management should take the necessary risks to promote the organization to outside world, in order to delivering the solution to society, and seeking the funds.

9. The implementation of three line of defence within the organization is not clear. It will impact to ineffective and inefficient good corporate governance (GCG), that has strong relationship with the risk management implementation within organization. Need agreement from top management regarding the organization structure that conform to the three lines of defence model. The model will strengthen the GCG within the organization.

Below are the key notes taken from the 20 academic staff regarding to current situation and their expectations on the risk management implementation at ITB:

1. All respondents do not feel the presence of the risk management practices. The risk is very rare discussed specifically. There is no risk assessment on the ITB's strategic plan. Annual work plans and budgeting are more technical in nature and only focus on the academic activities. Talented students are decreasing, and at the same time ITB's reputation is also decreasing, in the long run this situation will lead to risk of existence.

2. There are several reasons why the presence of risk management is not that strong:

- The leadership and commitment from top management is not at the same level. There is unclear tone from the top regarding the risk management implementation.

- ITB has many faculties and schools, and each has its own culture. This situation creates a silo approach to risk management practice across the organization. The risk culture still does not exist within the organization as a whole. It is felt that the ITB organization is less agile, it is difficult to change. Dependence on individuals is very high, and does not rely on robust systems. The ITB's strong brand image has caused the organization to underestimate many things, including the implementation of risk management.

- The risk management is still new to ITB, that need some times to internalize it into the organization. Some respondents even don't know about the risk management. There is no risk management socialization and training to the academic staff. Risk awareness within organization is still low, with a very limited information. There is a perception that risk management doesn't create values to the organization, it is only an additional work to the current process ( $\mathrm{ad}$ hoc).

3. ITB must rely on itself, in terms of capacity, funding, and portfolios. ITB must use its own strength. There must be a risk assessment, where all risks taken into consideration. One of the solutions is that human resources department should develop the top management's career path in the context of managerial leadership, including the risk management leadership.

4. All respondents expect the risk management to be applied at ITB at the soonest. As a leading university in Indonesia, and recognized in the world, ITB should have the courage to take and manage the necessary risks to keep maintaining the academic quality, and at the end will improve the university ranking and competitiveness locally and globally. The leadership and competence are correlated each other to the ranking of ITB. This leadership includes the risk management leadership. ITB as a big and well-known organization should conduct the good corporate governance, to protect its reputation, academic quality, and increase its competitive edge. The implementation of risk management can be carried out in an integrated and comprehensive manner within ITB organization.

5. In order to accelerate this implementation, organization needs a change management, so that the organization can grow steadily and sustain in the long run. It is to be expected that the implementation of risk management at ITB is the same as 


\section{International Journal of Current Science Research and Review}

ISSN: 2581-8341

Volume 04 Issue 12 December 2021

DOI: 10.47191/ijesrr/V4-i12-16, Impact Factor: 5.825

IJCSRR@ 2021

www.ijjesrr.org

applied in other corporations, where there is existence of policy, procedure, risk management champions, and risk management system. People who lead the organization must understand the vision and mission of the organization. The strategy must also consider the culture within. ITB has to manage the culture by using change management. It really depends on the culture.

6. The implementation of risk management at ITB should use a top-down approach, where the strategic matters are at the top management level. There must be a strong leadership and commitment from top management and transmit the risk culture to all levels of management within the organization.

Below are the key highlights taken from the questionnaires result regarding to current situation and their expectations on the risk management implementation at ITB:

1. Around $66 \%$ of respondents think that risk can have a negative and positive impact, the rest still have a negative perception of risk. This negative perception will reflect the attitude towards the risk itself, where the human tendency will avoid the negative things. However, in reality, not all risks can be completely avoided but should be managed accordingly. Only $87 \%$ of the respondents agree that risk management is everybody's business, and only $79 \%$ agree that Rector should hold the highest accountability in risk management implementation at ITB.

2. Around $58 \%$ of respondents believe that the decision-making process has partially considered the potential risk. Only $24 \%$ believe that process has fully considered the risks. Other than that, not sure and not yet considered at all.

3. Almost $90 \%$ of the respondents believe that risk management will increase organization's values, and increase the competitiveness of the organization.

4. There are different perceptions related to the extent to which risk management implementation has been carried out at ITB. Some respondents believe the risk management has been done intuitively without any formalization, some believe the risk management has been formalized but there is no adequate training and socialization, and some don't have any idea on the extent of implementation.

5. In general, there are top 5 risks faced by ITB: reputation risk, HR planning risk, strategy risk, operational risk, and unsupportive organization culture.

6. Around $40 \%$ of the respondents do not know the ITB's risk management practice compare to other state-owned University in Indonesia. Only $21 \%$ believe ITB has a better risk management implementation compared to its competitors locally.

7. The top 3 major challenges in implementing risk management are: requires strong leadership and commitment from top management, difficult to change the way of working and/or organization's culture, and requires a high commitment and consumes a lot of time.

8. Most of the respondents (around $87 \%$ ) believe that risk management should be implemented at institution wide level.

9. The majority of respondents do not know the risk management model. However, from the respondents who familiar with the risk management standards, most of the respondents know and prefer the SNI ISO-31000.

\section{CONCLUSION}

Based on the literatures, benchmarking to competitors in Indonesia and Singapore, and interview's results with the subject matter experts and academic staff, there are 5 key results that can be withdrawn as per below:

1. There are different perception and understanding between the academic staff regarding to enterprise risk management practice. There is also a perception that risk management doesn't create values to the organization, it is only an additional work to the current process (ad hoc). The differences prove that there are still unalignment among academic staff, that need to be resolved to have the same understanding of the risk management concept. Apart from the differences, all respondents believe that the risk management should provide the preventive actions instead of reactive. Most of the respondents believe that the implementation of an efficient risk management will increase organization's values, and at the same time increase the competitiveness of the organization. Overall, the existence of risk management concept has been reflected individually, however not in an integrated manner yet.

2. The enterprise risk management concept is not fully applied within organization. The risk is rarely discussed specifically in the management meeting. Most of the respondents do not know the enterprise risk management implementation, since there is no socialization or training related to this matter from the top management of ITB. In the strategic plan, there is no risk 


\section{International Journal of Current Science Research and Review}

ISSN: 2581-8341

Volume 04 Issue 12 December 2021

DOI: 10.47191/ijesrr/V4-i12-16, Impact Factor: 5.825

IJCSRR@ 2021

Www.ijesrr.org

assessment at all. Annual work plans and budgeting are more technical in nature and only focus on the activities. The implementation of risk management is still sporadic and reactive, not preventive. There are no comprehensive anticipatory actions, where the application of risk management is still at normative level. The risks just been considered intuitively without using any particular framework. Currently, there is no risk management unit at ITB.

3. The risk awareness is still perceived low. ITB has many faculties and schools, and each has its own culture. This situation creates a silo approach to risk management practice across the organization. Most of the respondents do not see the same level of risk leadership and commitment between the top management. Leadership and commitment have not been fully demonstrated by top management, who should have established the risk management roadmap, systems and structures. ITB is a state university with a legal entity, which requires strategic and managerial leadership to run its organization. At ITB there is no managerial leadership development, where the top management is heavily experience in research activities during their tenure serving the University. This managerial leadership also includes the risk leadership management. The lack of knowledge and skill regarding enterprise risk management practice are also become the major issues for top management in terms of leading the risk management implementation at ITB.

4. Almost all respondents expect the risk management to be applied immediately. A sufficient socialization and training related to risk management at the lecturer level is highly regarded. As a leading university in Indonesia, and recognized in the world, ITB should have the courage to take and manage the necessary risks to keep maintaining the academic quality, research and innovation, that at the end will improve the university ranking and competitiveness locally and globally. The leadership and competence are correlated each other to the ranking of ITB. This leadership includes the risk management leadership. ITB as a big and well-known organization should also conduct the good corporate governance, to protect its reputation, academic quality, and increase its competitive edge. The implementation of risk management at ITB should use a top-down approach, where the strategic matters are at the top management level. Objectives must be aligned from top to bottom, and the same perception across the organization regarding the implementation of risk management is highly expected. There must be a strong leadership and commitment from top management and transmit the risk culture to all levels of management within the organization. The organization structure of risk management itself should be directly report to the Rector. The implementation of risk management should be carried out in an integrated and comprehensive manner within ITB organization. Top management should ensure the efficient and effective way in socializing the risk management practices to all stakeholders. ITB should operate like a corporation and not only focus on the academic excellence, where there is an existence of policy, procedure, risk management champions, and risk management system. If not change, the market will shrinkage down. Rector holds the highest accountability to meet the demand or create the demand. Academic must be innovative, and must stay relevant with the external and internal context. In order to accelerate this implementation and manage the culture, organization needs a change management, so that the organization can grow steadily and sustain in the long run. Most of the respondents believe that risk management should be implemented at institution wide level. The majority of respondents do not know the risk management model. However, from the respondents who familiar with the risk management standards, most of the respondents know and prefer the ISO-31000.

5. It is strongly recommended for ITB to implement the enterprise risk management based on ISO-31000. ISO-31000 has been used and widely accepted by the corporations as their risk management standard. ISO-31000 focuses squarely on risk management and its role in strategic planning and decision-making, providing guidance on the nature of the ERM and how to implement it. ISO-31000 is oriented more toward using risk management to generate organization's value, rather than risk reduction and risk avoidance. ISO-31000 also has been used as the risk management standard at University of Indonesia (UI), and Bogor Agricultural Institute (IPB). Both universities are state-owned, and most likely have the same characteristics with ITB as Higher Education Institution that implements the activities of teaching, research, and community service in all fields, disciplines, and environment. Therefore, it is preferable for ITB to adopt ISO-31000 as its risk management standard.

\section{REFERENCES}

1. Alijoyo, A., \& Fisabilillah, A.F.M.S., 2021, Risk Management Implementation in Public Sector Organizations: A Case Study of Indonesia, Organizational Cultures: An International Journal, 22(1). 


\section{International Journal of Current Science Research and Review}

ISSN: 2581-8341

Volume 04 Issue 12 December 2021

DOI: 10.47191/ijcsrr/V4-i12-16, Impact Factor: 5.825

IJCSRR@ 2021

www.ijesrr.org

2. Board of Trustees' Decree of Institut Teknologi Bandung (ITB) No: 17/I1.MWA/KP/2019, Appointment of Members of the Governance Committee of the ITB's Board of Trustees, 31 July 2019, Bandung, INA.

3. Board of Trustees' Decree of Institut Teknologi Bandung (ITB) No: 007/IT1.MWA/SK-KP/2021, Appointment of Members of the Audit and Risk Management Committee of the ITB's Board of Trustees for Period 2021-2022, 2 August 2021, Bandung, INA.

4. Committee of Sponsoring Organizations of the Treadway Commission (COSO), 2017, COSO - Enterprise Risk Management: Integrating with Strategy and Performance ( $2^{\text {nd }}$ ed), New York, USA.

5. Government Regulation of the Republic of Indonesia Number 60, 2008, Government Internal Control System, Jakarta, INA.

6. Government Regulation of the Republic of Indonesia Number 65, 2013, Statute of Institut Teknologi Bandung, Jakarta, INA.

7. Hampton, John J., 2015, Fundamentals of Enterprise Risk Management: How top companies assess risk, manage exposure, and seize opportunity ( $2^{\text {nd }}$ ed), New York, USA: American Management Association.

8. Hopkin, Paul., 2010, Fundamentals of Risk Management: Understanding, evaluating, and implementing effective risk management, London, UK: Kogan Page Limited.

9. Hubbard, Douglas W., 2009, The Failure of Risk Management: Why it's broken and how to fix it, New Jersey, USA: John Wiley \& Sons, Inc.

10. Itb.ac.id, 2021, Board of Officials. Available from https://www.itb.ac.id/board-of-officials [Accessed on 22 October 2021].

11. Itb.ac.id, 2021, Organization Chart. Available from https://www.itb.ac.id/organization-chart [Accessed on 23 October 2021].

12. Mwa.itb.ac.id, 2021, Komite Audit dan Manajemen Risiko. Available from https://mwa.itb.ac.id/komite-auditdanmanajemen-risiko [Accessed on 31 August 2021].

13. Mwa.itb.ac.id, 2021, Tentang MWA. Available from https://mwa.itb.ac.id/tentang-mwa [Accessed on 23 October 2021].

14. Nanyang Technological University (NTU), 2018, Standard Operating Procedures: Risk Management, Singapore, SG.

15. Ntu.edu.sg, 2021, Risk Management. Available from https://www.ntu.edu.sg/ase/safety-portal2/risk-management [Accessed on 14 November 2021].

16. Nus.edu.sg, 2021, Risk Management. Available from https://www.nus.edu.sg/ormc/risk-management [Accessed on 1 September 2021].

17. Padro, Fernando F., 2014, A conceptual framework on establishing a risk management framework within existing university assessment and evaluation practices, Studies in Learning, Evaluation, Innovation and Development (SLEID), 10(1).

18. Priyarsono, D.S., Widhiani, A.P., \& Sari, D.L., 2019, Starting the Implementation of Risk Management in a Higher Education Institution: The Case of IPB University, IOP Conference Series: Materials Science and Engineering, 598 012107.

19. Rector's Decree of Institut Teknologi Bandung No: 508/IT1.A/SK-KP/2021, The Risk Management Study Team of Institut Teknologi Bandung, 2 June 2021, Bandung, INA.

20. Sa.itb.ac.id, 2021, Tentang Senat Akademik. Available from https://sa.itb.ac.id/tentang-sa [Accessed on 23 October 2021].

21. Sidorenko, A., \& Demidenko, E., 2017, Guide to effective risk management 3.0, Research Gate.

22. The Australian New Zealand Risk Management Standard (AS/NZ)), 2004, AS/NZ 4360: Risk Management (3 $3^{\text {rd }}$ ed), Sydney, AUS.

23. The International Organization for Standardization (ISO), 2018, ISO 31000: Risk management - Guidelines (2 ${ }^{\text {nd }}$ ed), Geneva, $\mathrm{CH}$.

24. Universitas Indonesia (UI), 2016, Manual: The Risk Management of Universitas Indonesia, Depok, INA.

25. Yudianto et al., 2021, The Influence of Enterprise Risk Management Implementation and Internal Audit Quality on Universities' Performance in Indonesia, Journal of Southwest Jiaotong University, 56(2).

Cite this Article: Johan Candra (2021). Enterprise Risk Management (ERM) Practices to Achieve Long Term and Sustainable Organization's Goals: Case of Institut Teknologi Bandung (ITB). International Journal of Current Science Research and Review, 4(12), 1720-1728 